\title{
Electric Energy Management for Plug-in Electric Vehicles Charging in the Distribution System by a dual cascade scheduling algorithm
}

\author{
Supipat Panichtanakom \\ Prince of Songkla University, \\ Faculty of Engineering, Department of Electrical \\ Engineering \\ Hatyai, Songkla, Thailand \\ Kanapacame@hotmail.com \\ Kusumal Chalermyanont \\ Prince of Songkla University, \\ Faculty of Engineering, Department of Electrical \\ Engineering \\ Hatyai, Songkla, Thailand \\ Kusumal.c@psu.ac.th
}

\begin{abstract}
This paper presents an algorithm for plug-in electric vehicles (PEVs) charging in the three-phase distribution system for residential houses. It aims to prevent violent voltage level deviation and increasing losses on the three-phase distribution system due to uncontrolled charging and allocate power to each plug-in electric vehicle. The algorithm is comprised of two processes. The first process is power limitation and limited power of load imbalance by if-else rules, while the second process is power allocation to each PEV by the dual cascade scheduling algorithm which is the integration of tasking scheduling algorithms. A 100 kVA distribution transformer and 30 houses are defined in the simulation situation. Also, the available PEVs in single-phase, two-phase, and threephase systems are assigned forverification of the proposed algorithm. Root-mean-square deviation (RMSD) referred to the satisfaction of PEV owners, total PEVs charged energy, and the average percentage of achieved charging time, as the result indicators. The results show the proposed algorithm can provide good results without rejected PEVs charging. Furthermore, this paper also displays the analysis of voltage level, percentage of voltage unbalance factor, and loss in the distribution system. In the future, coordination with home appliances to gain a high load margin or electric energy cost control will be improved in the proposed algorithm.
\end{abstract}

Keywords: Electric energy management, Plug-in electric vehicles charging, Dual cascade scheduling algorithm

\section{INTRODUCTION}

Nowadays, Plug-in Electric Vehicles (PEVs) are of interest to many countries because they offer a reduction in the volatility of fuel costs due to the operation of global markets and also because of environmental concerns. Moreover, a variety of research studies have proposed novel technologies for PEVs such as energy management for PEVs charging, battery technology, and charging or discharging technology.

The uncontrolled PEVs charging may cause problems in the distribution system, such as voltage level deviation, increased losses in the distribution system [1], and a decrease in transformer lifetime. When many PEVs are plugged into the distribution system at the same time, high electricity consumption occurs, which causes the voltage to drop, especially at the farthest locations on the transmission line [2], [3]. Moreover, excessive domestic consumption can increase the temperature of transformers, causing deterioration of their insulation and decreasing transformer lifetime [4]-[6].

The electric energy required for PEV charging consists of two variables: power and time. Power management methods are based on controlling the electric energy required by a PEV in a limited time. Fuzzy logic power control algorithms [7] are capable of increasing the charging power when consumption is low and decreasing it when consumption is high. However, rapidly increasing the power level may reduce battery lifetime. Time control methods are used when the power is limited and are suitable for fully charging batteries with no impact on the distribution system. The principle of time control methods is to search for periods of low 
consumption and persuade PEV owners to charge during those periods by reducing the price of electricity during those periods [8]. Examples of this method are the ant colony algorithm [9], game theory [10], [11], valley filling [12], [13], genetic algorithm (GA) [14], geneticintelligent scatter search algorithm (GA-ISS) [15], home energy management [16]-[21], and priority scheduling [22]-[28]. However, these algorithms mostly aim to get more energy and low cost but do not take into account the impacts of voltage levels and unbalanced voltage levels in the three-phase system according to the standard, which would affect the efficiency of the power distribution system and does not represent the maximum and minimum achieved PEVs charging and PEV owner satisfaction level. Moreover, they are also complex, hard to implement, and have the possibility of causing new peak power. Therefore, this paper presents the algorithm that is a simple method, easy to implement, and operates real-time scheduling.

The scheduling algorithms are based on the requested time and available time to generate a weight for sorting PEVs charging. The scored priority scheduling [23] adopts the fuzzy logic to generate a weight while the real-time scheduling [29] uses a ratio of the requested time and available time and the improved queuing-theory-based scheduling [30] applies available time to sort PEVs. All scheduling algorithms have a single weight for sorting PEVs and intend to provide PEVs charging success which may cause some PEVs to be rejected. Also, algorithms can get confused when sorting PEVs with the same weight.

In this paper, the case study in Thailand was chosen because electric vehicles are gaining interest from the central government, and urgent policy for implementation-defined. However, research on the topic continues to progress slowly because of the lack of statistical information concerning vehicle usage, information on people's needs, and other measures used with PEVs charging. Paper [31] published in the proceeding shows PEVs charging by the load shaving method based on TOU (Time of Use) rates, which is a study of PEVs charging on two rates of electric energy price in two periods. It is unsuitable for PEVs charging to gain high electric energy while keeping electric energy costs low.

In this paper, simple electric energy management for PEVs charging in the three-phase distribution system for the residential houses is proposed. The management process can be divided into two processes. First, the power available is calculated based on the identification of the power margin and the limitation of load unbalance in a three-phase distribution system to control voltage level according to the standard and improve losses in the distribution system. The second process is power allocation using the dual cascade scheduling algorithm. The power and load unbalance are limited by if-else rules, and the charging power of PEVs is allocated by the dual cascade scheduling algorithm based on simple task-scheduling algorithms [32] in the computer $\mathrm{CPU}$ processing-time-allocation system. The dual cascade scheduling algorithm consists of the RR-SJF-EDF-LJF-FCFS scheduling algorithm and the SJF-RR-EDF-LJF-FCFS scheduling algorithm. The RR-SJF-EDF-LJF-FCFS scheduling algorithm is applied if there are available PEVs in the single-phase and twophase systems. On the other hand, the SJF-RR-EDFLJF-FCFS scheduling algorithm is employed when the available PEVs are in the three-phase system. The contribution of the proposed algorithm is increased performance of electric energy management of the threephase system for the postponing investment to extend the capacity of the distribution system with preventing violent voltage level deviation and increasing losses on the three-phase distribution system. The algorithm has the advantage of being an online procedure with no need for a forecasting algorithm. It just uses the existing system structure and devices. Therefore, it will be possible to implement such a system immediately. The results of this study show that the algorithm can limit power and load unbalance in a three-phase system. Moreover, the dual cascade scheduling algorithm can provide good results without the rejection of PEVs charging. In the future, the proposed algorithm should be improved with coordination with home appliances to achieve a high load margin.

This paper is organized as follows: in section 2, the dual cascade scheduling algorithms are introduced, then section 3 deals with the statement of the problem, and the system profiles and system parameters are defined. Section 4 presents the methods, and section 5 illustrates and discusses the results of the simulation model and section 6 offers conclusions.

\section{DUAL CASCADE SCHEDULING ALGORITHM}

The dual cascade scheduling algorithm based on task management in a computer is proposed in this paper for scheduling PEVs charging. The five principles of CPU scheduling algorithms are applied to allocate electric power to PEVs, including First-Come-First-Serve (FCFS), Shortest-Job-First scheduling (SJF), Longest-Job-First scheduling (LJF), Round-Robin scheduling (RR), and Earliest-Deadline-First scheduling (EDF). The PEVs charging scheduling is based on the charging time for each PEV to schedule and every criterion is applied to decide the order of charging PEVs. The arrival time and departure time are employed by FCFS and EDF to sort the PEVs charging. The charging time is used by LJF, and the time difference between available time and requested time is employed by SJF. The RR scheduling averages the achieved charging time.

The dual cascade scheduling algorithm comprises two cascade scheduling algorithms that involve the overlapping of five scheduling algorithms, as shown in Fig. 7 and Fig. 8. The first cascade scheduling algorithm is the SJF-RR-EDF-LJF-FCFS scheduling algorithm, and the second is the RR-SJF-EDF-LJF-FCFS scheduling algorithm. The objective is problem-solving when the 
system has the same data. For instance, if some PEVs have the same time differences, which the SJF scheduling algorithm is unable to sort charging, the next scheduling algorithm is applied to sort PEVs charging, such as RR scheduling, EDF scheduling, LJF scheduling, or FCFS. Table 1 presents the characteristics of the five scheduling algorithms from a preliminary experiment of a single scheduling algorithm. This paper sets the priority of the result indications to be Root-MeanSquare Deviation (RMSD), which refers to the satisfaction of PEV owners, the total PEVs charged energy, the average percentage of achieved charging time, and the minimum percentage of achieved charging time of each PEV. The table shows that the SJF scheduling algorithm can provide low RMSD or high satisfaction of PEV owners, but there are some opportunities where the lowest priority may not be implemented. Next, the RR scheduling algorithm offers a high average percentage of achieved charging time with a few opportunities where some PEVs are rejected. The EDF scheduling algorithm gives high total PEVs charged energy, but there are some opportunities where the lowest priority may not be implemented and there is no guarantee of satisfaction for PEV owners. Likewise, the LJF scheduling algorithm gives high actual power but still has disadvantages like the EDF scheduling algorithm. Last, the FCFS scheduling algorithm enables smooth PEVs charging. However, it has disadvantages similar to the EDF and LJF scheduling algorithms.

Table 1. The characteristics of five scheduling algorithms

\begin{tabular}{|c|c|c|}
\hline Algorithms & Advantages & Disadvantages \\
\hline FCFS & $\begin{array}{l}\text { 1. Getting good } \\
\text { continuity of } \\
\text { PEVs charging. }\end{array}$ & $\begin{array}{l}\text { 1. Getting low results. } \\
\text { 2. There is no guarantee of } \\
\text { satisfaction for PEV owners. } \\
\text { 3. There are some opportunities } \\
\text { where the lowest priority may } \\
\text { not be implemented. }\end{array}$ \\
\hline SJF & $\begin{array}{l}\text { 1. Getting } \\
\text { satisfaction for } \\
\text { PEV owners. }\end{array}$ & $\begin{array}{l}\text { 1. More complexity to sort } \\
\text { charging. } \\
\text { 2. There are some opportunities } \\
\text { where the lowest priority may } \\
\text { not be implemented. }\end{array}$ \\
\hline LJF & $\begin{array}{l}\text { 1. Getting high } \\
\text { actual power. }\end{array}$ & $\begin{array}{l}\text { 1. There are some opportunities } \\
\text { where the lowest priority may } \\
\text { not be implemented. } \\
\text { 2. There is no guarantee of } \\
\text { satisfaction for PEV owners. }\end{array}$ \\
\hline $\mathrm{RR}$ & $\begin{array}{l}\text { 1. Getting high } \\
\text { average value. }\end{array}$ & $\begin{array}{l}\text { 1. Getting high interruption. } \\
\text { 2. There is no guarantee of } \\
\text { satisfaction for PEV owners. }\end{array}$ \\
\hline EDF & $\begin{array}{l}\text { 1. Getting good } \\
\text { results. }\end{array}$ & $\begin{array}{l}\text { 1. There is no guarantee of } \\
\text { satisfaction for PEV owners. } \\
\text { 2. There are some opportunities } \\
\text { where the lowest priority may } \\
\text { not be implemented. }\end{array}$ \\
\hline
\end{tabular}

\section{PROBLEM STATEMENT}

\subsection{MODEL OF THE DISTRIBUTION SYSTEM}

The distribution system used in this paper consists of a single distributed transformer and 30 houses. The power rating of the transformer is $100 \mathrm{kVA}, 3$ phases, $400 / 230 \mathrm{~V}, 50 \mathrm{~Hz}$. The distribution transformer supplies electricity to the 30 houses, consisting of 2 feeders with 15 houses in each feeder. It is assumed that each house has one PEV plugged in through a control box, which enables two-way communication between the control box and the control centre. When each PEV sends data through the control box to the control centre, the control centre will evaluate and send commands to the control box for PEV charging as communicated to the control centre, as shown in Fig. 1.

\subsection{TRANSFORMER LOAD PROFILE}

The actual load profile of the 100 kVA distribution transformer is shown in Fig. 2. This graph shows the electric energy consumption for each phase in 24 hours. It can be seen that the high power consumption period generally occurs between 16:00 and 23:00 hours. The power level arranged in descending order from 17:00 to 23:00 hours is phase $A$, phase $C$, and phase $B$, respectively. The maximum power is around $17 \mathrm{~kW}$ and unbalance is observed. The minimum power is around 100 watts, occurring from 9:00 to 14:00 hours.

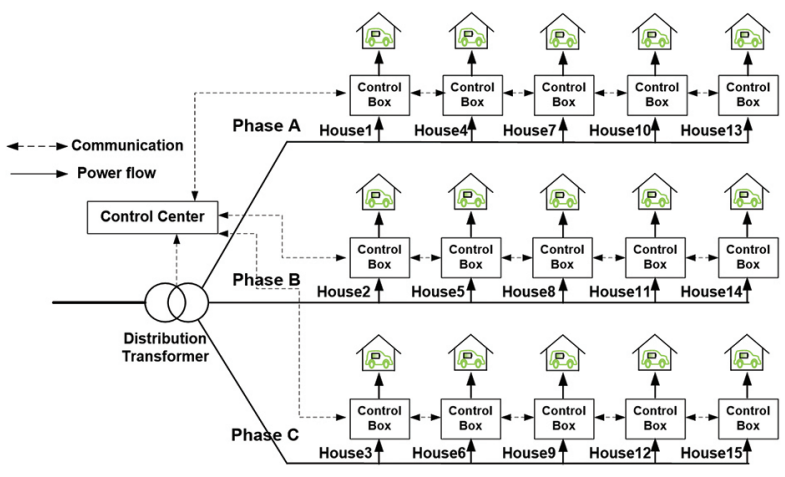

Fig. 1. Representation of one feeder

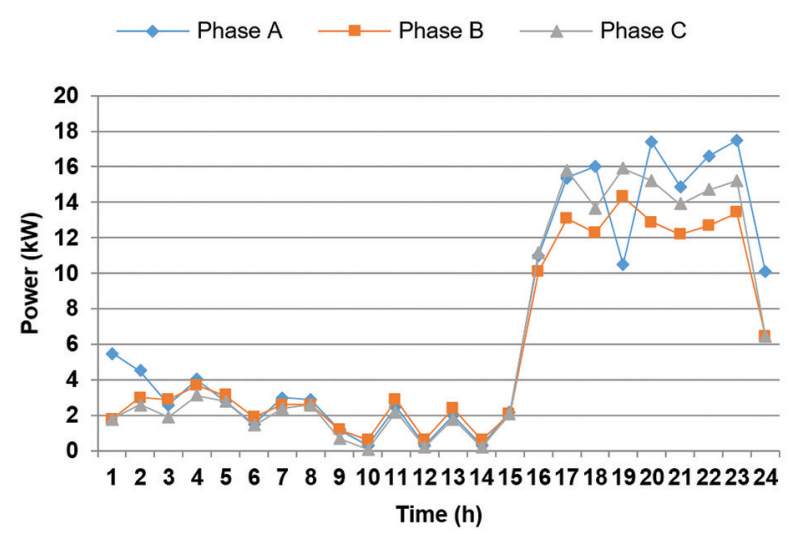

Fig. 2. The actual load profile of the $100 \mathrm{kVA}$ distribution transformer 


\subsection{TYPE OF PEVS}

To render the simulation close to a realistic system, three types of PEVs with different battery energy have been chosen, as follows [33]: 16 kWh Mitsubishi i-MiEV, 24 kWh Nissan Leaf, and 53 kWh Tesla Roadster. They are randomly used by the 30 houses.

\subsection{DEFINITIONS OF SYSTEM PARAMETERS}

The parameters for electric power and related time used in this paper are defined in Table 2 and Table 3, respectively. Table 2 displays the definition of electric power used in the simulation, which consists of battery charging power defined as $2 \mathrm{~kW}$, limited power as $27 \mathrm{~kW}$ per phase calculated at the rating power of the distribution transformer and safety factor, a limited power of unbalanced load assigned $4 \mathrm{~kW}$, load margin is between a limited power and load profile, and phase unbalanced power is between the maximum power and actual power.

Table 3 illustrates the definitions of related charging times used in the simulation. The available time is calculated by the arrival time and departure time. The requested time is calculated by the capacity of the battery $\left(E_{B C}\right)$, the end percentage of the state of charge $\left(E_{\text {SOCe }}\right)$ and the start percentage of the state of charge $\left(E_{\text {SOCs }}\right)$, the efficiency of the charger $(\eta)$, and the battery charging power $\left(P_{c h}\right)$. The charging time is the relationship between the available time and the requested time. That is, when the requested time is more than the available time, the charging time is the available time. On the other hand, if the requested time is less than the available time, the charging time is the requested time. The time difference is between available time and requested time. Moreover, it can refer to the urgent necessity of the PEV owner.

Table 6 in the appendix presents a summary of all the parameters assumed for each PEV, such as the energy of the battery $\left(E_{B C}\right)$, the battery charging power $\left(P_{c h}\right)$, the efficiency of the charger $(\eta)$, the start percentage of the state of charge $\left(E_{\text {socs }}\right)$, the end percentage of the state of charge $\left(E_{\text {soce }}\right)$, the arrival time $\left(T_{\text {arrival }}\right)$, the departure time $\left(T_{\text {departure }}\right)$, the available time $\left(T_{\text {available }}\right)$, the requested time $\left(T_{\text {requested }}\right)$, the charging time $\left(T_{\text {charging }}\right)$, and the time difference $\left(T_{\text {diff }}\right)$. Since the accumulation of PEVs from their arrival times to departure times in phases $A, B$ and $C$ are different, the system has an unbalanced load.

Table 2. The definition of electric power used in the simulation

\begin{tabular}{|cc|}
\hline Electric power & Specification values \\
\hline Battery charging power $(P c h)$ & $2 \mathrm{~kW}$ \\
\hline $\begin{array}{c}\text { Limited power (Plimit) } \\
\text { Limited power of unbalanced } \\
\text { load (Plimit,un) }\end{array}$ & $27 \mathrm{~kW}$ \\
\hline Load margin (Pmar) & $4 \mathrm{~kW}$ \\
\hline $\begin{array}{c}\text { Phase unbalanced power } \\
(P A, \text { un, } P B, \text { un, } P C, \text { un })\end{array}$ & $P A$, un $(t)=$ Pmax $(t)-P A, \operatorname{ch}(2)$ \\
& $P B$, un $(t)=$ Pmax $(t)-P B, \operatorname{ch}(3)$ \\
& $P C$, un $(t)=\operatorname{Pmax}(t)-P C, \operatorname{ch}(4)$
\end{tabular}

Table 3. The definition of related of charging times used in the simulation

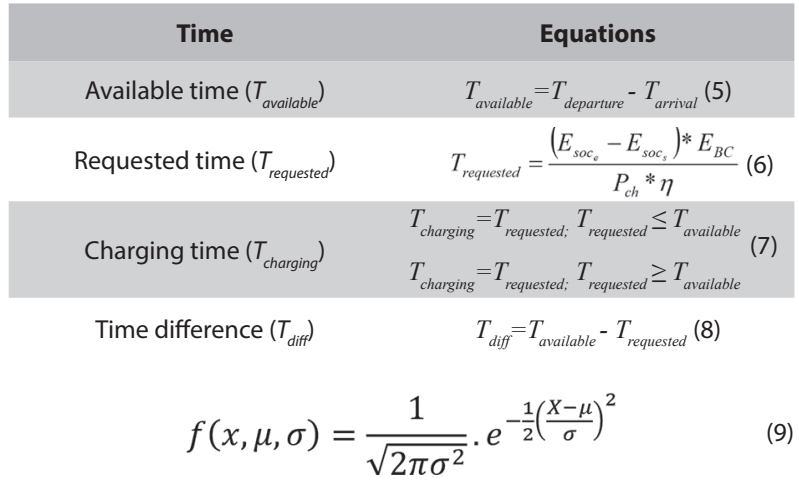

Where is

$\sigma$ Standard deviation value

$\mu$ Mean value

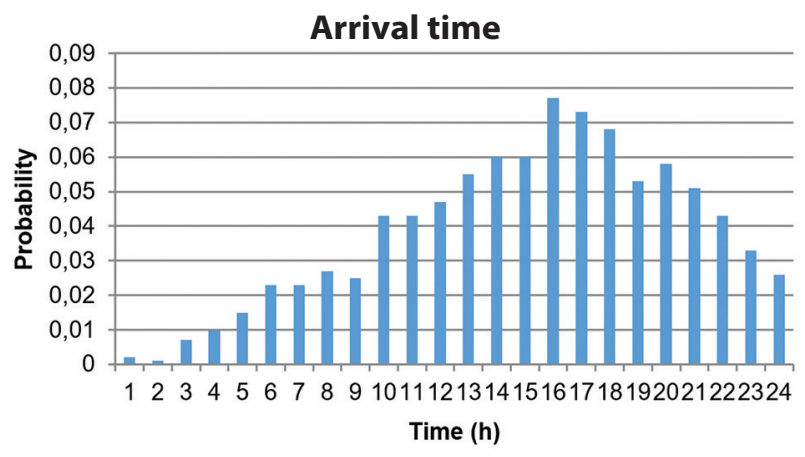

Fig. 3. The probability of arrival time of PEVs in phase A

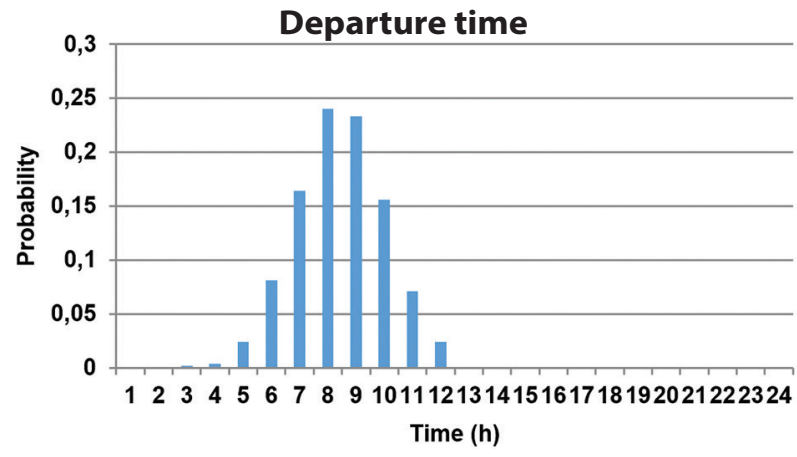

Fig. 4. The probability of departure time of PEVs in phase $A$

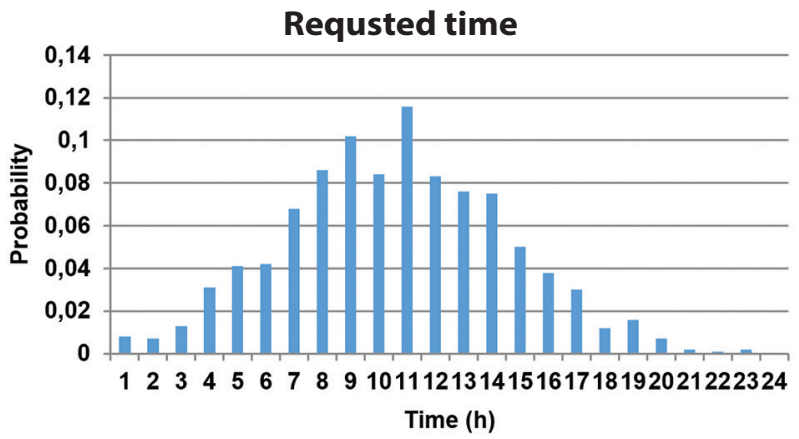

Fig. 5. The probability of requested time of PEVs in phase $A$ 


\section{METHOD}

\subsection{SYSTEM CONSTRAINTS}

In this paper, the algorithm proposed has been performed to control PEV charging under the following two constraints:

- The actual power $\left(P_{\text {actual }}\right)$ is power profile $\left(P_{\text {pro }}\right)$ added to the actual battery charging power of all PEVs $\left(P_{A, c h^{\prime}} P_{B, c h^{\prime}} P_{C, c h}\right)$ comprising of phases $A$, $B$, and $C$. It must not be higher than the limited power of the transformer $\left(P_{\text {limit }}\right)$.

$$
\begin{gathered}
P_{A, \text { actual }}(t)=P_{A, \text { pro }}(t)+P_{A, \text { ch }}(t) \\
P_{B, \text { actual }}(t)=P_{B, \text { pro }}(t)+P_{B, \text { ch }}(t) \\
P_{C, \text { actual }}(t)=P_{C, \text { pro }}(t)+P_{C, \text { ch }}(t) \\
P_{\text {actual }} \leq P_{\text {Limit }}
\end{gathered}
$$

- The maximum power of unbalanced load in each phase $\left(P_{\max , u n}\right)$ is the maximum difference in power between maximum power and the actual battery charging power of all PEVs $\left(P_{c h}\right)$ in each phase shown in (2)-(4). It must be less than or equal to the limited power of the unbalanced load $\left(P_{\text {limit, un }}\right)$.

$$
P_{\max , \text { un }} \leq P_{\text {Limit }, \text { un }}
$$

\subsection{RESULT INDICATORS}

- Root-mean-square deviation (RMSD): the average deviation of value difference between the requested time and achieved charging time. RMSD refers to the satisfaction of PEV owners.

$$
R M S D=\left(\frac{1}{N} \sum_{i=1}^{N}\left(T_{\text {request }, i}-T_{\text {achieved }, i}\right)^{2}\right)^{\frac{1}{2}}
$$

- Total PEVs charged energy: the algorithm aims to maximize the total electric energy to all PEVs and the electric energy consumption from the distribution transformer.

$$
\text { Total PEVs Charged Energy }=\sum_{i=1}^{N} E_{i}
$$

where $E_{i}$ is the electric energy of $i^{\text {th }} \mathrm{PEV}, N$ is the number of PEVs

- The average percentage of achieved charging time: The charging time is arranged to achieve the maximum average charging of all PEVs.

$$
\text { Average } \% T_{\text {achieved }}=\frac{\sum_{i=1}^{N} T_{i}}{N}
$$

Where $T_{i}$ is the percentage of achieved charging time of $i^{\text {th }}$ PEV, and $N$ is the number of PEVs.

A flow chart of the energy management of PEVs charging is illustrated in Fig. 6. It consists of two main processes. The first process is to calculate limited power in the system including load margin, unbalanced power, etc., while the second process is applying the dual cascade scheduling algorithms to allocate charging power to the PEVs by using the functions set out in the previous section. In the first step of the first process, the variables for the algorithm are defined, consisting of the battery charging power $\left(P_{c h}\right)$, the limited power $\left(P_{\text {limit }}\right)$, and the limited power of unbalanced load $\left(P_{\text {limit, un }}\right)$. Subsequently, the data for each PEV is collected from the commencement of charging, comprising their arrival time $\left(T_{i \text {, arrival }}\right)$, departure time $\left(T_{i \text {, departure }}\right)$, the total battery charging power of all PEVs required in each phase $\left(P_{A, P E V}(t), P_{B, P E V}(t), P_{C, P E V}(t)\right)$ and the transformer's load profile $\left(P_{\text {load pro }}(t)\right)$. The third step involves calculating the phase loading margins $\left(P_{A, \text { mar }}(t), P_{B, \text { mar }}(t), P_{C, \text { mar }}(t)\right)$, the power of unbalanced load of each phase $\left(P_{A, \text { un }}(t), P_{B \text {, un }}(t)\right.$, $\left.P_{C \text {, un }}(t)\right)$, the requested time $\left(T_{i \text {, request }}\right)$, the available time $\left(T_{i}\right.$, available $)$ and time difference $\left(T_{i, \text { diff }}\right)$, as well as the charging time $\left(T_{i, \text { charging }}\right)$ by using (1)-(8). Then the maximum and minimum values of the loading margin $\left(P_{\max \operatorname{mar}}(t), P_{\min }\right.$ mar $(t))$ and power of unbalanced load $\left(P_{\text {max , un }}(t), P_{\text {min, un }}(t)\right)$ are selected. In the next step, the total available charging power of all the PEVs in each phase $\left(P_{A, c h}(t), P_{B, c h}(t), P_{c, c h}(t)\right)$ are selected between the minimum values of the total battery charging power of all the PEVs $\left(P_{A, P E V}(t), P_{B, P E V}(t), P_{C}\right.$, PEV $(t))$ and the loading margin of each phase $\left(P_{A, \text { mar }}(t), P_{B,}\right.$ mar $\left.(t), P_{C \text { mar }}(t)\right)$. Then the maximum power of unbalanced load $\left(P_{\text {max un }}(t)\right)$ can be computed and checked within the system constraints shown in (12). If the maximum power of unbalanced load $\left(P_{\text {max, un }}(t)\right)$ exceeds the limited power of unbalanced load $\left(P_{\text {limit, un }}\right)$, PEVs with $2 \mathrm{~kW}$ charging capacity are eliminated one at a time until the system is restored to the constraints. In this step, the system will get the maximum actual power. The final step of the first process is to calculate the total number of PEVs that can be charged in each phase of the distribution system based on the actual battery charging power of all PEVs $\left(P_{A, c h}(t)\right.$, $\left.P_{B, c h}(t), P_{C, c h}(t)\right)$.

In the second process, the situation is evaluated every hour. The number of PEVs from the first process is scheduled by the dual cascade scheduling algorithms shown in Fig. 7. It shows the specific PEVs charging schedule of phase A. There are three conditions for PEVs scheduling. In the first condition, if the power margin $\left(P_{\text {mar }}\right)$ is more than the battery charging power of all PEVs $\left(P_{A \text {, }}\right.$ $\left.{ }_{P E V}\right)$, the controller commands the charging of all PEVs. In the second condition, when the power margin is less than the battery charging power of all PEVs and there are available PEVs in the single-phase and dual-phase, the controller uses the RR-SJF-EDF-LJF-FCFS for PEVs charging schedule. In the last condition, both the power margin is less than the charging power and there are available PEVs in the three-phase system, so the controller applies the SJF-RR-EDF-LJF-FCFS for PEVs charging 
schedule. This algorithm is an online system. Therefore, it is repeated every hour to evaluate the situation of the system and adjusts the newly calculated value. It will be repeated until a stop command is achieved.

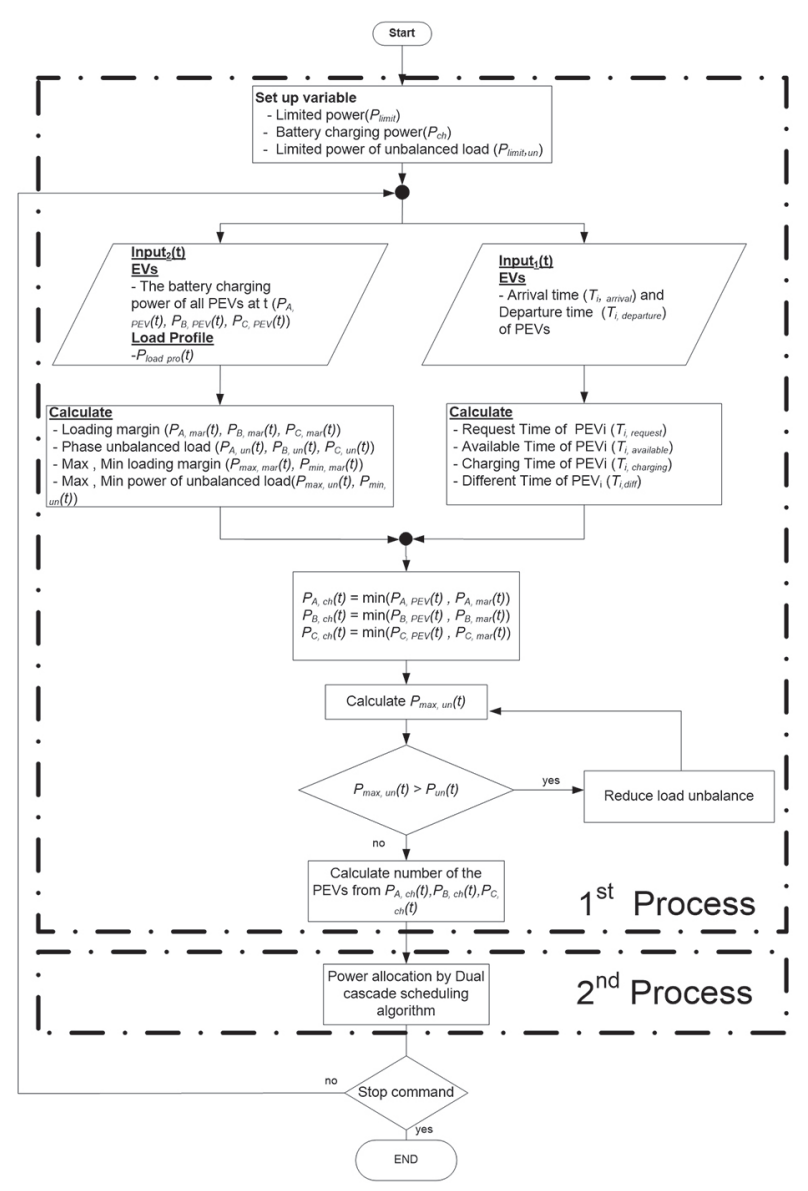

Fig. 6. Flow chart of electric energy management for PEV charging

\section{SIMULATION RESULTS AND DISCUSSION}

\subsection{SIMULATION RESULTS}

Table 5 reveals the simulation results of coordinating PEVs charging in the electricity distribution system for residential houses. The simulation scenarios consist of three PEVs penetration levels and occurring PEVs load balance and imbalance in the three-phase distribution system. The uncontrolled charging and four scheduling algorithms, which consist of the dual cascade scheduling algorithm, the scored priority scheduling, the realtime scheduling algorithm, and the improved queuingtheory-based scheduling, are applied for power allocation to each PEV.

First, the simulation results of $25 \%$ PEVs penetration level are illustrated in Table 5. Occurring PEVs load in the single-phase system is the first scenario. The uncontrolled charging, even though provides the best RSMD, total PEVs charged energy, and the average percentage of achieved charging time but violates the constraints of power limitation and power of unbal- anced. In contrast, all four algorithms can control power under constraints. However, the dual cascade scheduling algorithm provides the best percentage average of achieved charging time, $23.8 \%$.

Next, appearing PEVs load in the two-phase system is $50 \%$ of the PEVs penetration level. Likewise, the uncontrolled charging still provides the best results and violates the constraints, and the dual cascade scheduling algorithm providing RMSD, total PEVs charged energy, and the average percentage of achieved charging time is 6.4, $120 \mathrm{kWh}$, and $41.3 \%$, respectively is a good method for allocating power to each PEV, while other methods reject some PEVs charging, $0 \%$. For the $100 \%$ PEVs penetration level, the PEVs load presents in the three-phase system. The dual cascade scheduling algorithm that delivers 0.69, $554 \mathrm{kWh}$, and $99 \%$, is a good result for this scenario.

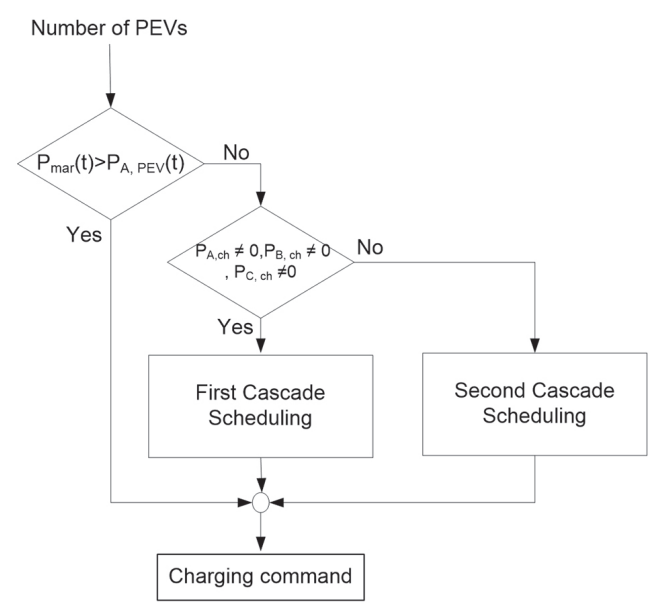

Fig. 7. Power allocation by the dual cascade scheduling algorithm in phase $A$

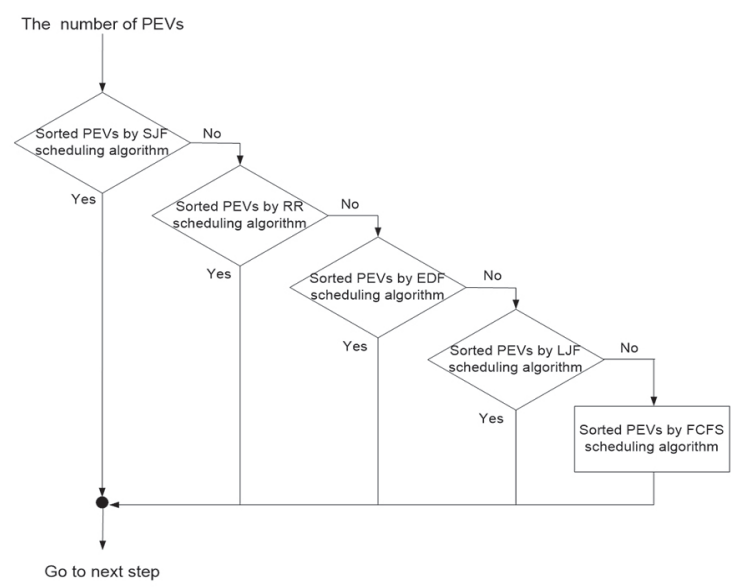

Fig. 8. The first cascade scheduling algorithm

Table 4. Comparison of loss in the power line

\begin{tabular}{|cccc|}
\hline \multicolumn{4}{c}{ Uncontrolled charging } \\
Phase A & Phase B & Phase C & Total \\
\hline $7,917.615$ & $8,343.459$ & $9,933.399$ & $26,194.473$ \\
\hline \multicolumn{4}{c}{ Controlled charging } \\
\hline $7,100.325$ & $8,278.902$ & $8,304.190$ & $23,683.417$ \\
\hline
\end{tabular}




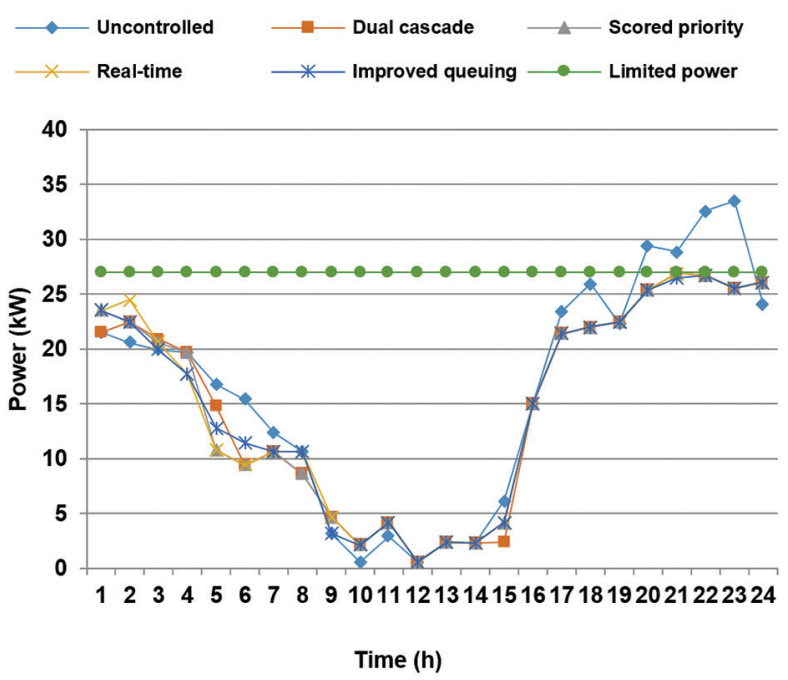

Fig. 9. The actual power of each scheduling algorithm
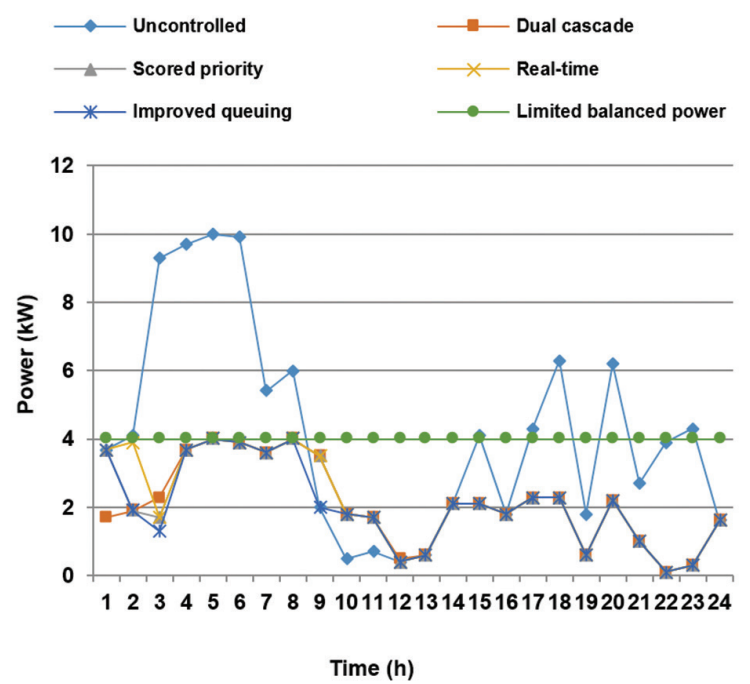

Fig. 10. Power of unbalanced load of all scheduling algorithms

Table 5. Simulation results of each method

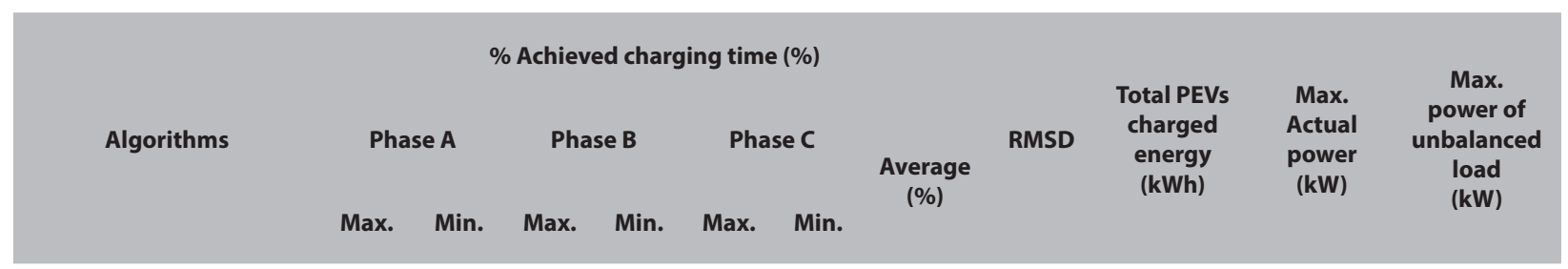

$25 \%$ PEVs penetration or 8 PEVs (Only 8 PEVs in phase A)

\begin{tabular}{|c|c|c|c|c|c|c|c|c|c|c|c|}
\hline Uncontrolled & \multicolumn{2}{|c|}{100} & - & - & - & - & 100 & 0 & 152 & 31.4 & 18.5 \\
\hline Dual cascade scheduling & 33.3 & 18.1 & - & - & - & - & 23.8 & 7.3 & 36 & 17.5 & 4.5 \\
\hline Scored priority & 44.4 & 11.1 & - & - & - & - & 23.1 & 7.3 & 36 & 17.5 & 4.5 \\
\hline Real-time scheduling & 45.4 & 10 & - & - & - & - & 23.1 & 7.3 & 36 & 17.5 & 4.5 \\
\hline $\begin{array}{l}\text { Improved queuing- } \\
\text { theory-based-scheduling }\end{array}$ & 45.4 & 10 & - & - & - & - & 23.1 & 7.3 & 36 & 17.5 & 4.5 \\
\hline
\end{tabular}

$50 \%$ PEVs penetration or $15 \mathrm{PEVs}(10 \mathrm{PEV}$ in phase $\mathrm{A}$, and $5 \mathrm{PEVs}$ in phase $\mathrm{B}$ )

\begin{tabular}{|c|c|c|c|c|c|c|c|c|c|c|c|}
\hline Uncontrolled & \multicolumn{2}{|c|}{100} & \multicolumn{2}{|c|}{100} & - & - & 100 & 1.2 & 288 & 31.7 & 16.2 \\
\hline Dual cascade scheduling & 37.5 & 22.2 & 100 & 46.6 & - & - & 41.3 & 6.4 & 120 & 19.4 & 4.0 \\
\hline Scored priority & 60 & 0 & 90.9 & 28.5 & - & - & 39.2 & 6.3 & 122 & 19.4 & 4.0 \\
\hline Real-time scheduling & 66.6 & 0 & 83.3 & 14.2 & - & - & 39.2 & 6.2 & 122 & 19.4 & 4.0 \\
\hline $\begin{array}{l}\text { Improved queuing- } \\
\text { theory-based-scheduling }\end{array}$ & 66.6 & 0 & 75 & 28.5 & - & - & 38.5 & 6.1 & 122 & 19.4 & 4.0 \\
\hline
\end{tabular}

$100 \%$ PEVs penetration of 30 PEVs (10 PEVs in phase A, 10 PEVs in phase $B$, and 10 PEVs in phase C)

\begin{tabular}{|c|c|c|c|c|c|c|c|c|c|}
\hline Uncontrolled & 100 & \multicolumn{2}{|c|}{100} & 100 & 100 & 0.54 & 560 & 30.9 & 6.3 \\
\hline Dual cascade scheduling & 100 & 100 & 87.5 & 100 & 99.0 & 0.69 & 554 & 26.9 & 4.0 \\
\hline Scored priority & 100 & 100 & 75 & 100 & 97.9 & 0.98 & 546 & 26.9 & 4.0 \\
\hline Real-time scheduling & 100 & 100 & 87.5 & 100 & 98.7 & 0.66 & 552 & 26.9 & 4.0 \\
\hline $\begin{array}{l}\text { Improved queuing- } \\
\text { theory-based-scheduling }\end{array}$ & 100 & 100 & 91.6 & 100 & 99.1 & 0.69 & 554 & 26.9 & 4.0 \\
\hline
\end{tabular}



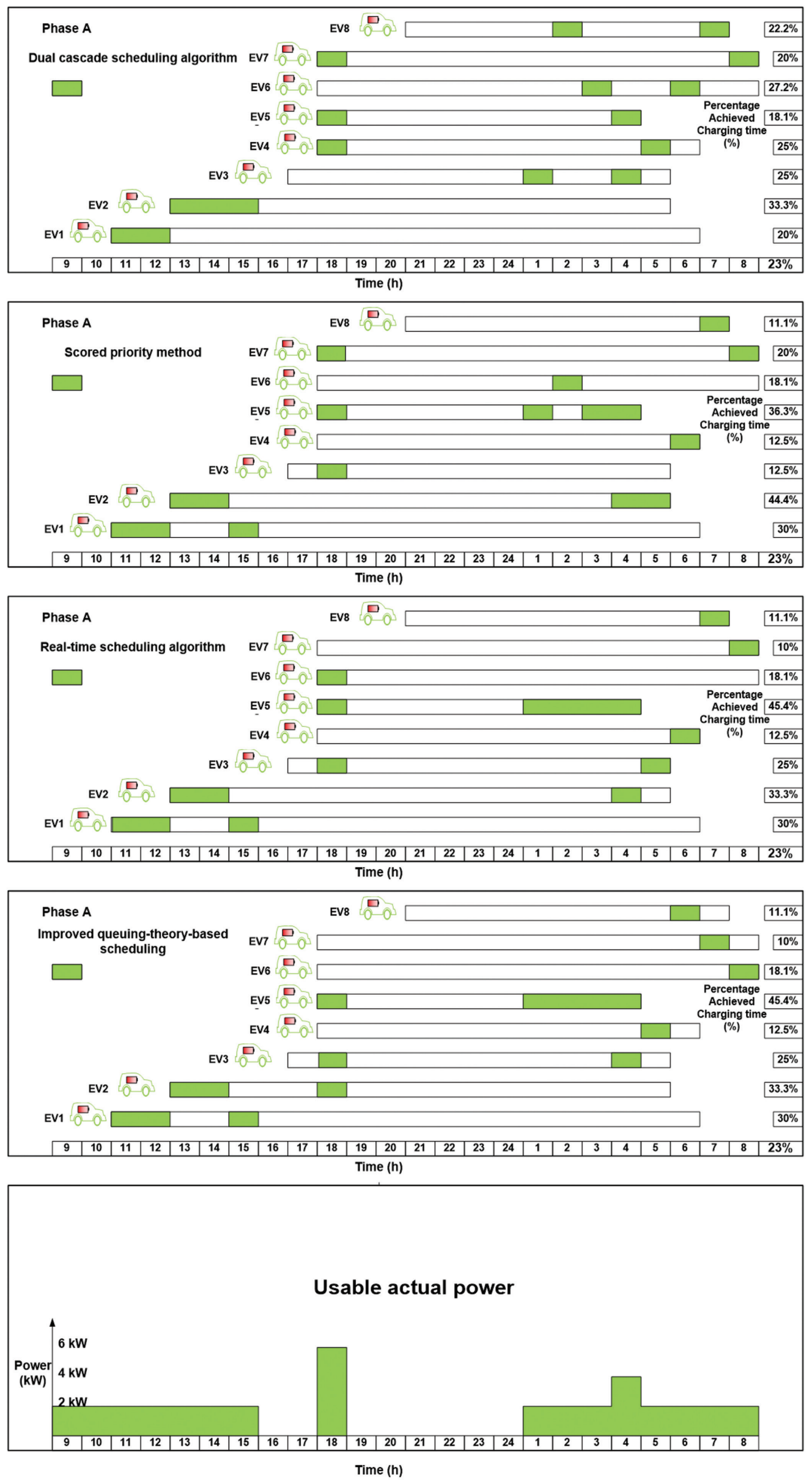

Fig. 11. PEVs charging behavior of each algorithm 


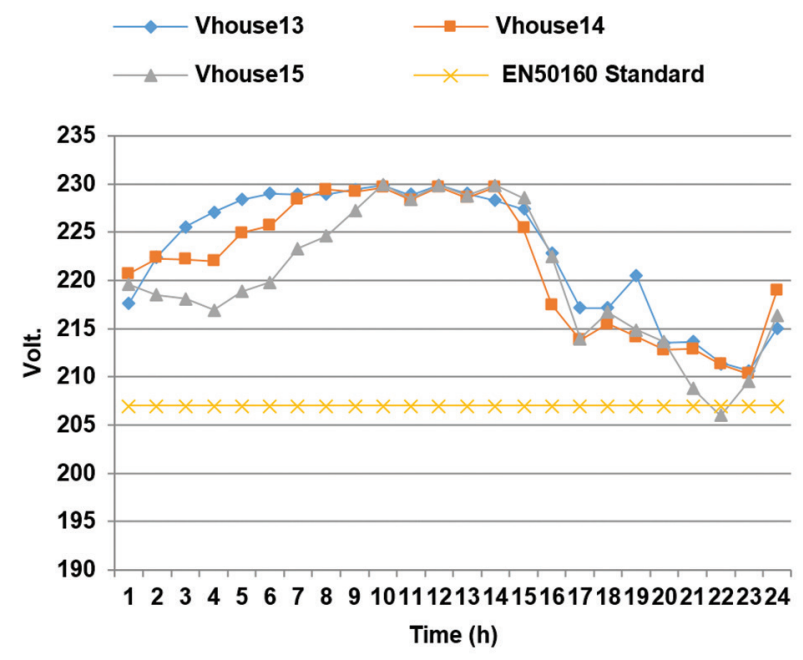

Fig. 12. Voltage level profiles the farthest houses under uncontrolled charging situation

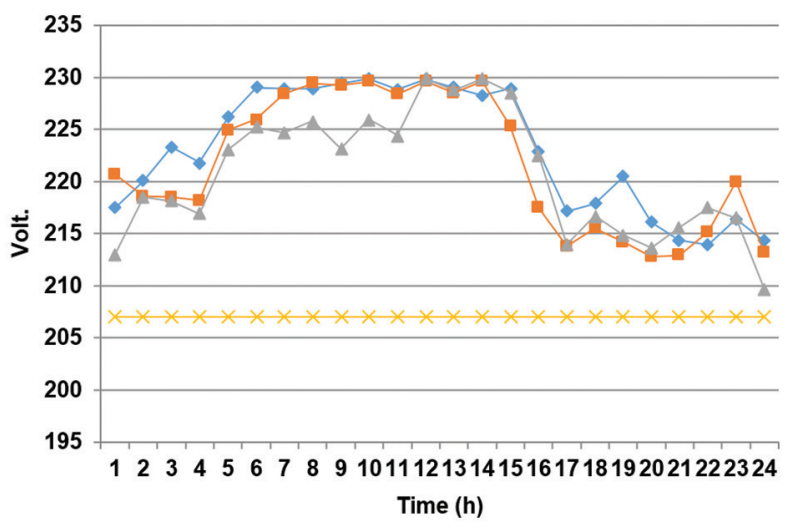

Fig. 13. Voltage level profiles the farthest houses under controlled charging situation

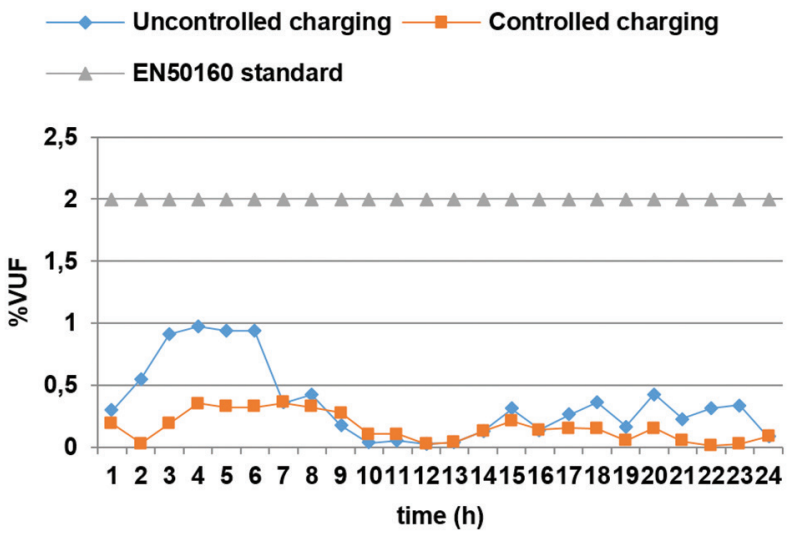

Fig. 14. Percentage of voltage unbalance factor profiles

\section{2 DISCUSSION}

For the results described above, all four scheduling algorithms can provide similar results because the input variables for processing are requested time and available time. However, the different processes will provide the different results as follows.
First, the dual cascade scheduling algorithm based on task management in a computer operation schedules PEVs charging by charging time gained from requested time and available time. Few opportunities exist that some PEVs are rejected from charging by this algorithm.

Second, the scored priority method based on fuzzy logic to generate the scores for PEVs scheduling [23] employing requested time and available time to be input variables of fuzzy mechanism can provide good RMSD in occurring PEVs load imbalance.

Next, the real-time scheduling algorithm based on the proportion between the requested time and the available time to schedule PEVs charging [29] provides quite a low average electric energy cost.

Finally, the improved queuing-theory-based scheduling algorithm based on the least slack time rate first scheduling for sorting PEVs charging [30] can result in good RMSD in appearing PEVs load imbalance and gives low average electric energy cost in some scenarios.

All scheduling algorithms based on requested time and available time to generate the weight for sorting PEVs are the simple method and provide good results, however, all three scheduling methods comprised scored priority method, real-time scheduling, and improved queuing-theory-based scheduling are inflexible methods. There is a high possibility to have rejected PEVs charging when there are PEVs in a single-phase or two-phase, moreover if the method gets data that have the same value, it can't sort the PEVs. The dual cascade scheduling algorithm can handle these problems. When there are PEVs in a single-phase or two-phase, it applies RR-SJF-EDF-LJF-FCFS to sort PEVs, and SJF-RREDF-LJF-FCFS is applied when there are PEVs in three phases, while it gets the same data the next scheduling algorithm is applied to sort PEVs such as shortestjob-first scheduling (SJF) for RR-SJF-EDF-LJF-FCFS and Round-Robin scheduling (RR) for SJF-RR-EDF-LJF-FCFS.

Fig. 9 reveals the actual power from using each scheduling algorithm. All lines have a similar shape and all scheduling algorithms can control power under power limitation, except uncontrolled charging, which takes the maximum power over limited power. The electrical devices in the distribution system may be damaged. Likewise, Fig. 10 illustrates the power of an unbalanced load from each scheduling algorithm. The uncontrolled charging provides high power, which violates the power of unbalanced load limitation. This result makes the voltage level drop and the electrical device may be damaged. From using each scheduling algorithm, the line graph displays that they can control the power of an unbalanced load under the constraint. The period of low power means there are many PEVs in the three-phase distribution system. In contrast, high power refers to having few PEVs and existing PEVs in the system unbalance.

Fig.11 presents the PEVs charging behavior of each algorithm. The 8 PEVs in a single-phase system is this 
situation. The solid color is PEV charging, and the transparent color is no PEV charging. The lowest chart shows the usable power resulting from the first process. The maximum power occurring from 18:00 to 19:00 hours is $6 \mathrm{~kW}$ which can charge 3 PEVs, and the minimum power is zero from 16:00 to 18:00 hours and 19:00 to 1:00 hours. In this situation, the dual cascade scheduling algorithm provides the average charging time, 2 hours, to each PEV while other algorithms offer the charging time under the urgent factor making some PEVs have short charging time, just an hour, or rejects charging.

Fig. 12 and Fig. 13 show voltage level profiles in the distribution system. Fig. 14 indicates the percentage of voltage unbalance factors (\%VUF) compared with standard EN50160 [34]. The distribution system consists of two feeders with 15 houses in each feeder. The backward/forward sweep method is applied to analyse the voltage level in the three-phase distribution system. Vhouse $_{13^{\prime}}$ Vhouse $_{14^{\prime}}$ and Vhouse ${ }_{15}$ are voltage levels of the farthest houses $\left(13^{\text {th }}, 14^{\text {th }}\right.$, and $15^{\text {th }}$ houses $)$ in phase $A$, phase $B$, and phase $C$, respectively.

The standard EN50160 defines the variation of voltage level to be $\pm 10 \%$ and the percentage of voltage unbalance factor (\%VUF) is lower than $2 \%$. Fig. 12 illustrates the voltage level based on the uncontrolled charging situation. The results show that the voltage level is lower than the standard at 22 hours. Fig. 13 indicates that the voltage levels of the farthest houses under controlled charging are above the standard, even in the worst case of phase C. Moreover, it can provide a better percentage of voltage unbalance factor, as shown in Fig. 14.

Table 4 indicates the comparison of losses in the power line. The losses in the power line decrease from $26,194.473$ watts to $23,683.417$ watts with the controlled charging.

In the future, the proposed algorithm should be improved to be able to coordinate control with home appliances for higher electric energy in PEVs charging.

\section{CONCLUSION}

A simple electric power management system for PEV charging of the electricity distribution system proposed consists of two processes. The first process calculates the usable power in the distribution system to control the charging power under the limited power and the limited power of the unbalanced load of the three-phase distribution transformer. The second process uses the dual cascade scheduling algorithms to optimally allocate power to PEVs under the power constraints. The achievement of management is measured by the value of root-mean-square deviation (RMSD), the total PEVs charged energy, and the average percentage of achieved charging time under the power and load unbalance limitation. The dual cascade scheduling algorithm consists of RR-SJF-EDF-LJF-FCFS and SJF-RR-EDF-LJF-FCFS for use with available PEVs in single, dual-phase and, three-phase systems. The results show that the dual cascade scheduling algorithm can provide good results and improve the possibility of PEVs charging rejection. This study demonstrates that the ability of the power distribution system to charge PEVs can be improved without the need to invest in increases in its capacity. Moreover, the proposed system has the advantage of being able to be implemented by simply installing a control box with a suitable plug-in at each house, after which the system can be controlled centrally at the distribution transformer without the need for any modification to the structure of the distribution system. In the future, the proposed algorithm will be improved to enable higher total PEVs charged energy by electric energy management to co-operate home appliances, especially the improvement of the cascade scheduling algorithm or studying other related methods.

\section{ACKNOWLEDGMENT}

This work was supported financially and through facility provision by the Faculty of Engineering and the Graduate School at Prince of Songkla University (PSU) and the Office of the Higher Education Commission (OHEC), Thailand. 


\section{APPENDIX}

Table 6. The summary of all variables of PEVs

\begin{tabular}{|c|c|c|c|c|c|c|c|c|c|c|c|}
\hline i & 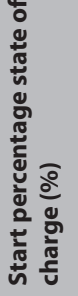 & 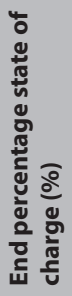 & 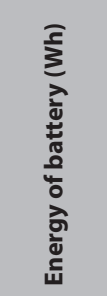 & 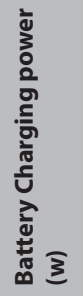 & 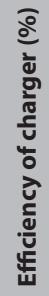 & 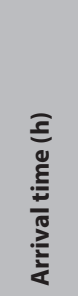 & 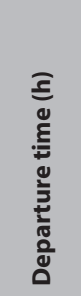 & 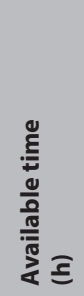 & 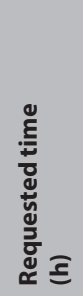 & 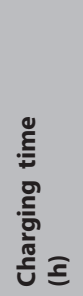 & 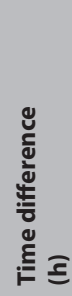 \\
\hline \multicolumn{12}{|c|}{ Phase A } \\
\hline 1 & 60 & 90 & 53,000 & 2,000 & 80 & $16: 00$ & 7:00 & 15.00 & 10.00 & 10.00 & 5.00 \\
\hline 2 & 50 & 90 & 53,000 & 2,000 & 80 & $20: 00$ & 8:00 & 12.00 & 14.00 & 12.00 & -2.00 \\
\hline 3 & 40 & 90 & 53,000 & 2,000 & 80 & 0:00 & 9:00 & 9.00 & 7.00 & 9.00 & -8.00 \\
\hline 4 & 50 & 90 & 24,000 & 2,000 & 80 & 17:00 & 10:00 & 17.00 & 6.00 & 6.00 & 9.00 \\
\hline 5 & 10 & 90 & 24,000 & 2,000 & 80 & 13:00 & 9:00 & 20.00 & 12.00 & 12.00 & 8.00 \\
\hline 6 & 20 & 90 & 24,000 & 2,000 & 80 & 16:00 & 7:00 & 15.00 & 11.00 & 11.00 & 4.00 \\
\hline 7 & 30 & 90 & 16,000 & 2,000 & 80 & 19:00 & 5:00 & 10.00 & 6.00 & 6.00 & 4.00 \\
\hline 8 & 50 & 90 & 16,000 & 2,000 & 80 & 14:00 & 6:00 & 16.00 & 4.00 & 4.00 & 12.00 \\
\hline 9 & 20 & 90 & 16000 & 2,000 & 80 & 21:00 & 6:00 & 9.00 & 7.00 & 7.00 & 2.00 \\
\hline 10 & 10 & 90 & 16,000 & 2,000 & 80 & 18:00 & 7:00 & 13.00 & 8.00 & 8.00 & 5.00 \\
\hline & Tota & & 295,000 & & & & & & & & \\
\hline
\end{tabular}

Phase B

\begin{tabular}{|c|c|c|c|c|c|c|c|c|c|c|c|}
\hline 1 & 60 & 90 & 53,000 & 2,000 & 80 & $22: 00$ & $6: 00$ & 8.00 & 10.00 & 8.00 & -2.00 \\
\hline 2 & 50 & 90 & 53,000 & 2,000 & 80 & $19: 00$ & 7:00 & 12.00 & 14.00 & 12.00 & -2.00 \\
\hline 3 & 40 & 90 & 53,000 & 2,000 & 80 & $17: 00$ & 8:00 & 15.00 & 17.00 & 15.00 & -2.00 \\
\hline 4 & 50 & 90 & 53,000 & 2,000 & 80 & 20:00 & 7:00 & 11.00 & 14.00 & 11.00 & -3.00 \\
\hline 5 & 20 & 90 & 53,000 & 2,000 & 80 & $19: 00$ & $6: 00$ & 11.00 & 24.00 & 11.00 & -13.00 \\
\hline 6 & 20 & 90 & 24,000 & 2,000 & 80 & $14: 00$ & 8:00 & 18.00 & 11.00 & 11.00 & 7.00 \\
\hline 7 & 40 & 90 & 24,000 & 2,000 & 80 & $15: 00$ & $6: 00$ & 15.00 & 8.00 & 8.00 & 7.00 \\
\hline 8 & 10 & 90 & 24,000 & 2,000 & 80 & $16: 00$ & 9:00 & 17.00 & 12.00 & 12.00 & 5.00 \\
\hline 9 & 20 & 90 & 16,000 & 2,000 & 80 & 21:00 & $10: 00$ & 13.00 & 7.00 & 7.00 & 6.00 \\
\hline \multirow[t]{2}{*}{10} & 30 & 90 & 16,000 & 2,000 & 80 & 0:00 & $6: 00$ & 6.00 & 6.00 & 6.00 & 0.00 \\
\hline & \multicolumn{2}{|c|}{ Total } & 369,000 & & & & & & & & \\
\hline
\end{tabular}

Phase C

\begin{tabular}{|c|c|c|c|c|c|c|c|c|c|c|c|}
\hline 1 & 60 & 90 & 53,000 & 2,000 & 80 & $15: 00$ & $7: 00$ & 14.00 & 10.00 & 10.00 & 2.00 \\
\hline 2 & 40 & 90 & 53,000 & 2,000 & 80 & $15: 00$ & $8: 00$ & 17.00 & 17.00 & 17.00 & 0.00 \\
\hline 3 & 50 & 90 & 53,000 & 2,000 & 80 & $20: 00$ & $8: 00$ & 12.00 & 14.00 & 12.00 & -2.00 \\
\hline 4 & 50 & 90 & 53,000 & 2,000 & 80 & $1: 00$ & 9:00 & 8.00 & 14.00 & 8.00 & -6.00 \\
\hline 5 & 40 & 90 & 53,000 & 2,000 & 80 & $19: 00$ & $8: 00$ & 13.00 & 17.00 & 13.00 & -4.00 \\
\hline 6 & 60 & 90 & 53,000 & 2,000 & 80 & $20: 00$ & $11: 00$ & 15.00 & 10.00 & 10.00 & 5.00 \\
\hline 7 & 50 & 90 & 53,000 & 2,000 & 80 & $21: 00$ & $7: 00$ & 10.00 & 14.00 & 10.00 & -4.00 \\
\hline 8 & 20 & 90 & 24,000 & 2,000 & 80 & $20: 00$ & $6: 00$ & 10.00 & 11.00 & 10.00 & -1.00 \\
\hline 9 & 10 & 90 & 24,000 & 2,000 & 80 & $23: 00$ & $4: 00$ & 5.00 & 12.00 & 5.00 & -7.00 \\
\hline \multirow[t]{2}{*}{10} & 30 & 90 & 16,000 & 2,000 & 80 & $16: 00$ & $6: 00$ & 14.00 & 6.00 & 6.00 & 8.00 \\
\hline & \multicolumn{2}{|c|}{ Total } & 435,000 & & & & & & & & \\
\hline
\end{tabular}




\section{REFERENCES}

[1] C. H. Dharmakeerthi, N. Mithulananthan, T. K. Saha, "Impact of electric vehicle fast charging on power system voltage stability", International Journal of Electrical Power \& Energy Systems, Vol. 57, 2014, pp. 241-249.

[2] N. Leemput, F. Geth, J. Van Roy, A. Delnooz, J. Buscher, J. Driesen, "Impact of Electric Vehicle On-Board Single-Phase Charging Strategies on a Flemish Residential Grid", IEEE Transactions on Smart Grid, Vol. 5, No. 4, 2014, pp. 1815-1822.

[3] K. Clement-Nyns, E. Haesen, J. Driesen, "The impact of vehicle-to-grid on the distribution grid", Electric Power Systems Research, Vol. 81, No. 1, 2011, pp. 185-192.

[4] G. Razeghi, L. Zhang, T. Brown, S. Samuelsen, "Impacts of plug-in hybrid electric vehicles on a residential transformer using stochastic and empirical analysis", Journal of Power Sources, Vol. 252, 2014, pp. 277-285.

[5] A. D. Hilshey, P. D. H. Hines, P. Rezaei, J. R. Dowds, “Estimating the Impact of Electric Vehicle Smart Charging on Distribution Transformer Aging", IEEE Transactions on Smart Grid, Vol. 4, No. 2, 2013, pp. 905-913.

[6] M. A. S. Masoum, P. S. Moses, K. M. Smedley, "Distribution transformer losses and performance in smart grids with residential Plug-In Electric Vehicles", Proceedings of ISGT 2011, Anaheim, CA, USA, 17-19 January 2011, pp. 1-7.

[7] A. A. Eajal, M. F. Shaaban, E. F. El-Saadany, K. Ponnambalam, "Fuzzy Logic-Based Charging Strategy for Electric Vehicles Plugged into a Smart Grid", Proceedings of the IEEE International Conference on Smart Energy Grid Engineering, Oshawa, ON, Canada, 17-19 August 2015, pp. 1-6.

[8] S. Shao, T. Zhang, M. Pipattanasomporn, S. Rahman, "Impact of TOU rates on distribution load shapes in a smart grid with PHEV penetration", Proceedings of PES T\&D 2010, New Orleans, LA, USA, 19-22 April 2010, pp. 1-6.

[9] S. Xu et al., "Ant-Based Swarm Algorithm for Charging Coordination of Electric Vehicles", International Journal of Distributed Sensor Networks, Vol. 9, No. 5, 2013, pp. 1-13.
[10] L. Xia, J. de Hoog, T. Alpcan, M. Brazil, I. Mareels, D. Thomas, "Electric Vehicle Charging: A Noncooperative Game Using Local Measurements", IFAC Proceedings Volume, Vol. 47, No. 3, 2014, pp. 5426-5431.

[11] Z. Zhu, S. Lambotharan, W. H. Chin, Z. Fan, "A Mean Field Game Theoretic Approach to Electric Vehicles Charging", IEEE Access, Vol. 4, 2016, pp. 3501-3510.

[12] K. Zhang et al., "Optimal decentralized valley-filling charging strategy for electric vehicles", Energy Conversion and Management, Vol. 78, 2014, pp. 537-550.

[13] L. Zhang, F. Jabbari, T. Brown, S. Samuelsen, "Coordinating plug-in electric vehicle charging with electric grid: Valley filling and target load following", Journal of Power Sources, Vol. 267, 2014, pp. 584-597.

[14] R. Mehta, D. Srinivasan, A. M. Khambadkone, J. Yang, A. Trivedi, "Smart Charging Strategies for Optimal Integration of Plug-In Electric Vehicles Within Existing Distribution System Infrastructure", IEEE Transactions on Smart Grid, Vol. 9, No. 1, 2018, pp. 299-312.

[15] T. Mao, X. Zhang, B. Zhou, “Intelligent Energy Management Algorithms for EV-charging Scheduling with Consideration of Multiple EV Charging Modes", Energies, Vol. 12, No. 2, 2019, pp. 1-17.

[16] M. Pipattanasomporn, M. Kuzlu, S. Rahman, "An Algorithm for Intelligent Home Energy Management and Demand Response Analysis", IEEE Transactions on Smart Grid, Vol. 3, No. 4, 2012, pp. 2166-2173.

[17] A. S. Masoum, S. Deilami, P. S. Moses, M. A. S. Masoum, A. Abu-Siada, "Smart load management of plug-in electric vehicles in distribution and residential networks with charging stations for peak shaving and loss minimisation considering voltage regulation", IET Generation, Transmission \& Distribution, Vol. 5, No. 8, 2011, pp. 877-888.

[18] S.Deilami, A.S. Masoum, P.S. Moses, M.A.S. Masoum, "Real-Time Coordination of Plug-In Electric Vehicle Charging in Smart Grids to Minimize Power Losses and Improve Voltage Profile", IEEE Transactions on Smart Grid, Vol. 2, No. 3, 2011, pp. 456-467. 
[19] Y. Azzougui and A. Recioui, "Hardware and software load power control in smart home applications based on Taguchi optimisation technique", Internationanl Journal of Intelligent Systems Design and Computing, Vol. 2, No. 3-4, 2018, pp. 203-223.

[20] A. Recioui, "Home Load-Side Management in Smart Grids Using Global Optimization",: Research Anthology on Multi-Industry Uses of Genetic Programming and Algorithms, IGI Global, 2021.

[21] A. Recioui, F. Z. Dekhandji, "Implementation of Load Control for Smart Metering in Smart Grids", Book chapter in: Optimizing and Measuring Smart Grid Operation and Control, IGI Global, 2021.

[22] B. Sun, Z. Huang, X. Tan, D. H. K. Tsang, "Optimal Scheduling for Electric Vehicle Charging With Discrete Charging Levels in Distribution Grid", IEEE Transactions on Smart Grid, Vol. 9, No. 2, 2018, pp. 624-634.

[23] E. Akhavan-Rezai, M. F. Shaaban, E. F. El-Saadany, F. Karray, "Online Intelligent Demand Management of Plug-In Electric Vehicles in Future Smart Parking Lots", IEEE Systems Journal, Vol. 10, No. 2, 2016, pp. 483-494.

[24] K. N. Kumar, B. Sivaneasan, P. L. So, "Impact of Priority Criteria on Electric Vehicle Charge Scheduling", IEEE Transactions on Transportation Electrification, Vol. 1, No. 3, 2015, pp. 200-210.

[25] K. W. Chan and X. Luo, "Real-time scheduling of electric vehicles charging in low-voltage residential distribution systems to minimise power losses and improve voltage profile", IET Generation, Transmission \& Distribution, Vol. 8, No. 3, 2014, pp. 516-529.

[26] B. Geng, J. K. Mills, D. Sun, "Two-Stage Charging Strategy for Plug-In Electric Vehicles at the Residential Transformer Level", IEEE Transactions on Smart Grid, Vol. 4, No. 3, 2013, pp. 1442-1452.
[27] Z. Wang and R. Paranjape, "Optimal scheduling algorithm for charging electric vehicle in a residential sector under demand response", Proceedings of the IEEE Electrical Power and Energy Conference, London, ON, Canada, 26-28 October 2015, pp. 45-49.

[28] E. Akhavan-Rezai, "Priority-based Charging Coordination of Plug-in Electric Vehicles in Smart Parking Lots", Proceedings of the IEEE PES General Meeting, National Harbor, MD, USA, 27-31 July 2014, pp. 1-5.

[29] J. Kang, S. J. Duncan, D. N. Mavris, "Real-time Scheduling Techniques for Electric Vehicle Charging in Support of Frequency Regulation", Procedia Computer Science, Vol. 16, 2013, pp. 767-775.

[30] P. Han, J. Wang, Y. Han, Y. Li, “Resident Plug-In Electric Vehicle Charging Modeling and Scheduling Mechanism in the Smart Grid", Mathmatical Problems in Engeering, Vol. 2014, 2014, pp. 1-8.

[31] S. Panichtanakom, K. Chalermyanont, S. Thienmontri, "Study of Plug-in Electric Vehicles Charging by Using Load Shaving Method Based on TOU in Distribution System: A Case Study in Thailand", Proceedings of the International Electrical Engineering Congress, Krabi, Thailand, 7-9 March 2018, pp. 1-4.

[32] A. Silberschatz, P. B. Galvin, G. Gagne, "Operating System Concepts", $9^{\text {th }}$ Edition, John Wiley \& Sons, Inc, 2012.

[33] M. Yilmaz and P. T. Krein, "Review of Battery Charger Topologies, Charging Power Levels, Infrastructure for Plug-In Electric and Hybrid Vehicles", IEEE Transactions on Power Electronics, Vol. 28, No. 5, 2013, pp. 2151-2169.

[34] H. Markiewicz, A. Klajn, "Voltage Disturbances Standard EN 50160 Voltage Characteristics in Public Distribution Systems", Wroclaw University of Technology, 2004. 